\title{
Short Communication: A Field Study on the Relationship Between Body Condition and Embryo Production in Superovulated Holstein Yearling Heifers
}

\author{
H. Kadokawa, ${ }^{\star 1}$ N. Tameoka, $†$ M. Uchiza,† Y. Kimura,† and M. Yonaił \\ ${ }^{*}$ Faculty of Agriculture, Yamaguchi University, Yoshida 1677-1, Yamaguchi 753-8515, Japan \\ †Japan National Livestock Breeding Center, Anaguchi 72-21, Shimo-Kuriyagawa, Morioka 020-0123, Japan \\ ‡Department of Animal Breeding and Reproduction, National Institute of Livestock and Grassland Sciences, Senbonmatsu 768, \\ Nasushiobara, Tochigi 329-2793, Japan
}

\section{ABSTRACT}

We conducted a field survey to estimate the relationship between embryo production and the body condition score (BCS) on a 5-point scale, as well as blood concentrations of insulin and glucose, in superovulated Holstein yearling heifers housed in a free-stall barn. They were provided total mixed rations to meet the nutrient requirements. The daily ration was divided between 2 feeding times, utilizing stanchions to separate heifers to avoid social status preventing inferior heifers from having enough feed. The recovered fluid after uterine flushing from heifers ( $\mathrm{n}=88,13$ mo old) was examined microscopically for the morphological grade and the development stage. The number of heifers in which BCS was $2.75,3.00,3.25$, and 3.50 was $6,35,40$, and 7 , respectively. The 3.50 BCS heifers produced fewer excellent grade embryos than 3.00 or 3.25 BCS heifers significantly. The 3.50 BCS heifers produced significantly more morula than $2.75,3.00$, or 3.25 BCS heifers. In contrast, $2.75 \mathrm{BCS}$ heifers produced more blastocysts than 3.25 or 3.50 BCS heifers. The 3.50 BCS heifers were hyperinsulinemic. Our results suggested no significant effect of BCS around 3.00 on embryo production, whereas 3.50 BCS heifers may have poorer embryo production.

Key words: blastocyst, body condition score, hyperinsulinemia, superovulation

The protocol for multiple ovulation in Holstein yearling heifers and embryo transfer (MOET) is widely used for genetic improvement of dairy cattle; however, the use of superovulation remains affected by high variability in the ovulatory response to hormonal treatment and by a variable number of transferable embryos. Various

Received August 26, 2007.

Accepted December 5, 2007.

${ }^{1}$ Corresponding author: hiroya@yamaguchi-u.ac.jp factors, including lactation, breed, and repeated superovulation, have been associated with variability in the ovulatory response in adult cow donors, as reviewed previously (Kafi and McGowan, 1997). However, these factors cannot explain the variability in the ovulatory response of nonlactating Holstein yearling heifers, which have not previously been treated for multiple ovulations. Although nutrition affects the superovulatory response in beef heifers and ewes, in which the nutritional status was treated experimentally (Nolan et al., 1998; Yaakub et al., 1999; Lozano et al., 2003), the mechanisms through which it affects the superovulatory response have not been fully clarified. Under field conditions, it is not always possible to quantify the nutrient content of the feed supplied to donors, and it is also not always possible to measure the energy status and blood concentrations of various metabolites and metabolic hormones during a MOET program, although a recent report suggested the association of hyperinsulinemia with fewer follicles and compromised oocytes for fertilization and blastocyst formation in moderately fat and well-fed heifers (Adamiak et al., 2005). The BCS is the only possible method to assume the nutritional status of a donor easily without an additional cost. However, little is known about the relationship between BCS and the number of collected transferable embryos in Holstein donor heifers under field conditions. Therefore, we conducted a field survey to estimate the relationship between the number of collected transferable embryos and BCS on a 5-point scale, as well as blood concentrations of insulin and glucose, on the day of uterine flushing in Holstein donor heifers.

Holstein heifers used in this survey $(\mathrm{n}=88,13 \mathrm{mo}$ old) were housed in a free-stall barn in the Iwate Station of the National Livestock Breeding Center, one of the largest farms utilizing the MOET program in Japan. Data were collected from donors superovulated between January 2005 and March 2007. They were provided TMR consisting largely of grass silage to meet the nutrient requirements according to the Japanese Feeding 
Standard (Agriculture, Forestry and Fisheries Research Council Secretariat, 1999). The feed volume per heifer per day was determined by the content of each lot of feed and by BW. The daily ration was divided between 2 feeding times: from 0900 to $0930 \mathrm{~h}$, immediately after removal of the remaining feed, and from 1600 to $1630 \mathrm{~h}$, utilizing stanchions to separate heifers to avoid social status preventing inferior heifers from having enough feed. However, because all heifers were allowed to eat the remaining feed at other times after being released from stanchions, the precise individual feed intake could not be measured in this survey study. Water and mineral blocks were provided ad libitum. Absence of diseases, including reproductive diseases, was confirmed by daily observation or by weekly rectal palpation with the aid of ultrasonography. All animals received human care according to law no. 105 and notification no. 6 and no. 22 of the Japanese Guidelines for Animal Care and Use.

Superovulatory treatment consisted of 8 i.m. injections during $4 \mathrm{~d}$ of decreasing doses of porcine $\mathrm{FSH}$ (Antrin-R, Kawasaki-Mitaka Pharmaceutical Co., Tokyo, Japan). The total FSH doses used were $24 \mathrm{arm}-$ our units $(5,5,4,4,2,2,1$, and 1 armour units for each injection). The $\mathrm{PGF}_{2 \alpha}$ analog $(0.75 \mathrm{mg}$ of cloprostenol, Estrumate, Sumitomo Chemical, Tokyo, Japan) was administered simultaneously with the seventh FSH injection. After confirming estrus, heifers were inseminated twice, about 48 and $60 \mathrm{~h}$ after the $\mathrm{PGF}_{2 \alpha}$ injection, using frozen-thawed semen. Rectal palpation was prohibited in the period of superovulatory treatment in the MOET program, because stress induced by humans may decrease the ovarian response against porcine FSH, and pressure from rectal palpation on ovaries may increase the inappropriate timing of ovulation.

At $1330 \mathrm{~h}$ on $\mathrm{d} 7 \mathrm{(d} 0=$ day of $\mathrm{AI})$, jugular blood was sampled and centrifuged at $12,000 \times g$ for $20 \mathrm{~min}$ at $4^{\circ} \mathrm{C}$, and plasma was harvested and stored at $-35^{\circ} \mathrm{C}$ until analysis. At $1430 \mathrm{~h}$ on d 7, embryos were collected by nonsurgical uterine flushing using a balloon catheter (Fujihira Industry Co. Ltd., Tokyo, Japan), and lactate Ringer solution (Fuso Pharmaceutical Industries Ltd., Tokyo, Japan) supplemented with $1 \%$ fetal calf serum, $100 \mathrm{U} / \mathrm{mL}$ of penicillin $\mathrm{G}$, and $0.1 \mathrm{mg} / \mathrm{mL}$ of streptomycin sulfate. The BCS of heifers was measured on a scale ranging from 1 (emaciated) to 5 (obese) with 0.25 spacing (Edmonson et al., 1989) on d 7. Rectal palpation with the aid of ultrasonography was performed to confirm the existence of corpus luteum after uterine flushing.

The recovered fluid was examined microscopically for quality grading of the recovered embryo according to the morphological criteria of quality and viability (Lindner and Wright, 1983; Callesen et al., 1995). Collected embryos were classified as excellent, good, fair, poor, degenerated, or unfertilized. The development stages of the embryo classified as excellent, good, fair, and poor were subclassified as morula, compact morula, blastocyst (including early blastocyst), or expanded blastocyst.

Plasma concentration of glucose was measured with an autoanalyzer (model-7170, Hitachi Co. Ltd., Tokyo, Japan) and commercial kit (Kainos Laboratories Inc., Tokyo, Japan). All samples were processed in a single assay with an intraassay coefficient of variation of less than $1.0 \%$ at $5.0 \mathrm{mM}$. Plasma insulin was assayed in duplicate with a commercial RIA kit (Insulin-Eiken, Eiken Chemical Co Ltd., Tokyo, Japan). All samples were processed in a single assay with a limit of detection of $10 \mathrm{p} M$ and an intraassay coefficient of variation of $5.8 \%$ at $148 \mathrm{p} M$.

We calculated the sum of the number of excellent grade embryos and the number of good grade embryos (excellent/good grade embryos) for each heifer. The number of each grade of embryo, the number of excellent/good grade embryos, and the number of each stage of embryo in each heifer were subjected to square root transformation. Data were analyzed using Statview (version 5.0 for Macintosh, SAS Inst. Inc., Cary, NC). For the square root of embryo production data, significance of the effect of BCS was evaluated by ANOVA followed by Fisher's protected LSD test. For plasma concentrations of glucose and insulin, significance of the effect of BCS was evaluated by ANOVA and Fisher's protected LSD test. Null hypothesis was rejected if the $P$-value was less than or equal to 0.05 to show significant difference among the different BCS groups; however, we showed the detailed $P$-value when it was less than or equal to 0.10 for the detailed discussion. All results are presented as the means \pm standard error of the means.

The number of heifers with a BCS score of 2.75, 3.00, 3.25 , or 3.50 was $6,35,40$, and 7 , respectively. We assumed that most of the remaining feed of $2.75 \mathrm{BCS}$ heifers had been consumed by 3.50 BCS heifers, because of the similar number of 2.75 BCS heifers and 3.50 BCS heifers. The 3.50 BCS heifers $(449 \pm 21 \mathrm{~kg})$ were heavier $(P<0.05)$ than $2.75(365 \pm 23 \mathrm{~kg}), 3.00$ $(380 \pm 10 \mathrm{~kg})$, and $3.25(403 \pm 9 \mathrm{~kg})$ BCS heifers, and 3.25 BCS heifers were heavier $(P<0.05)$ than 2.75 and 3.00 BCS heifers. However, there was no significant difference in metabolic BW among $2.75(83.5 \pm 10.5 \mathrm{~kg})$, $3.00(86.1 \pm 5.6 \mathrm{~kg}), 3.25(89.9 \pm 5.2 \mathrm{~kg})$, or $3.50(97.5$ $\pm 9.8 \mathrm{~kg}$ ) BCS heifers. The $2.75,3.00,3.25$, or $3.50 \mathrm{BCS}$ heifers produced $15.0 \pm 4.1$ (range from 3 to 27 ), 15.6 \pm 1.6 (0 to 36$), 11.3 \pm 1.5$ ( 0 to 35 ), and $10.0 \pm 2.7$ (2 to 20 ) embryos, respectively. All heifers responded to superovulation treatment; however, no embryo was col- 
(a) $\quad$ Significant difference as compared to BCS-3.00 donor heifer

$\longleftarrow$ Significant difference as compared to BCS-3.25 donor heifer
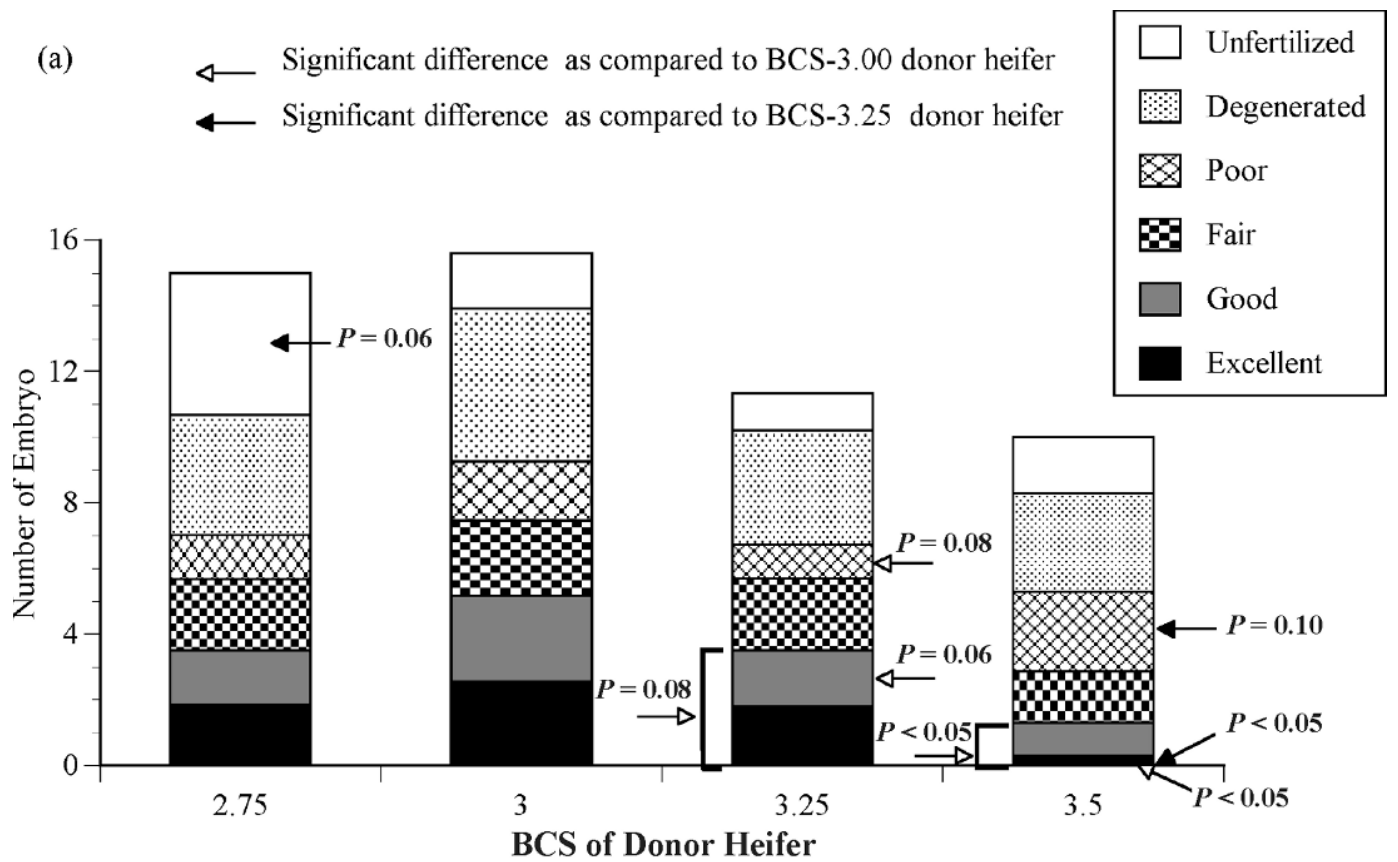

(b)
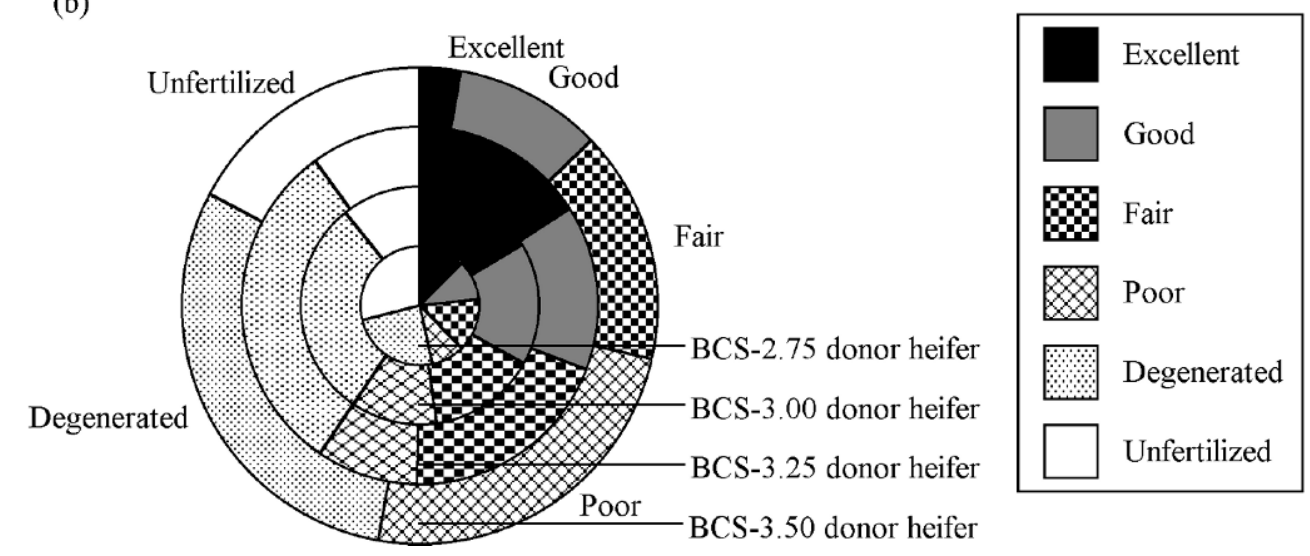

Figure 1. Relationship between BCS of donor heifers and embryo production shown as the morphological criteria of quality and viability, (a) number of each class of embryo and (b) proportion of each class of embryo to all collected embryos. In the concentric circle graph (b), the innermost zone, the next inner zone, the outer zone, and the outermost zone show the proportion of BCS-2.75, BCS-3.00, BCS-3.25, and BCS-3.5 donor heifers, respectively.

lected from one 3.00 BCS heifer and one 3.25 BCS heifer. There was no significant difference in almost all evaluated parameters (Figure 1a and $1 \mathrm{~b}$ ), including the number of excellent/good grade embryos, among 2.75, 3.00, and 3.25 BCS heifers. However, 3.25 BCS heifers produced fewer $(P<0.05)$ embryos than 3.00 BCS heifers.

The 3.50 BCS heifers produced fewer $(P<0.05)$ excellent grade embryos than 3.00 or 3.25 BCS heifers (Figure 1a). The 3.50 BCS heifers produced fewer $(P<0.05)$ excellent/good grade embryos than 3.00 BCS heifers (Figure 1a), and the $3.50 \mathrm{BCS}$ heifers had a lower ratio of excellent/good grade embryos to all collected embryos than $2.75,3.00$, or 3.25 BCS heifers, as shown in the concentric circle graph (Figure 1b), where the innermost zone, the next inner zone, the outer zone, and the outermost zone show the proportion of each class embryo to all collected embryos in BCS 2.75, 3.00, 3.25, and 3.5 donor heifers, respectively. The 2.75 BCS heifers tended to have more unfertilized oocytes than 3.25 BCS heifers $(P=0.06)$.

The 3.50 BCS heifers produced significantly more morula than $2.75,3.00$, or 3.25 BCS heifers (Figure 2a), and 3.50 BCS heifers had a higher ratio of morula to 
(a)

4 Significant difference as compared to BCS-2.75 donor heifer

4 Significant difference as compared to BCS-3.00 donor heifer

$\longleftarrow$ Significant difference as compared to BCS-3.25 donor heifer

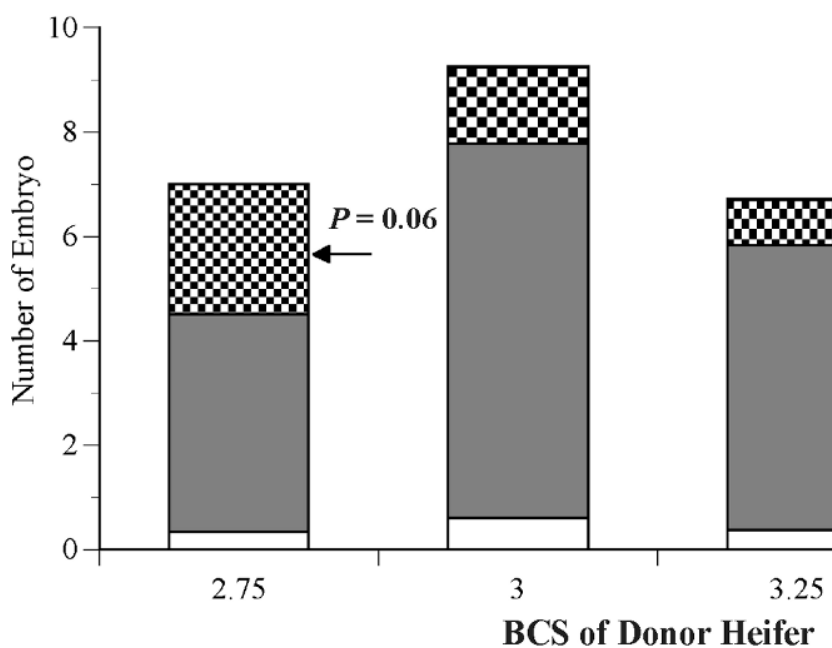

(b)

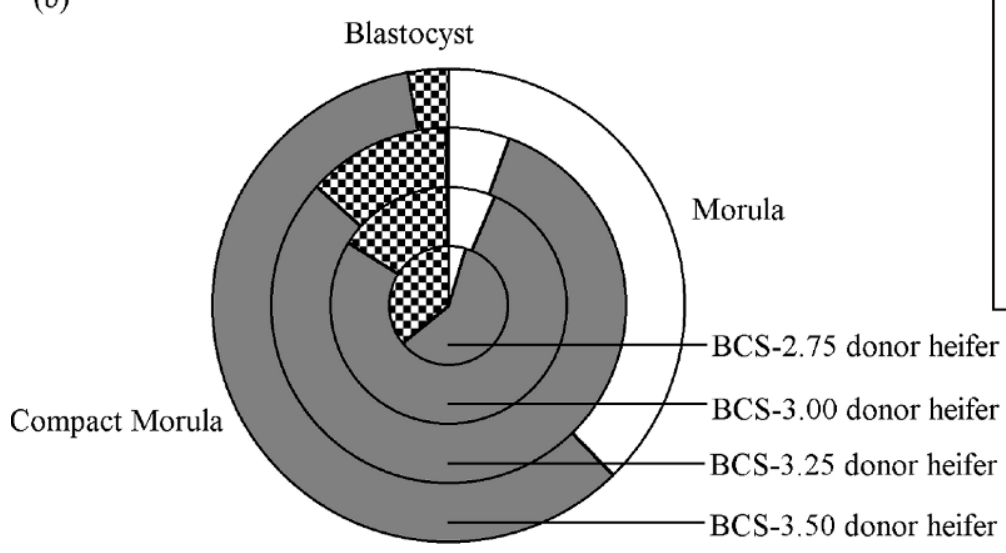

\section{BCS of Donor Heifer}

Expand Blastocyst

B Blastocyst

Compact Morula

Morula
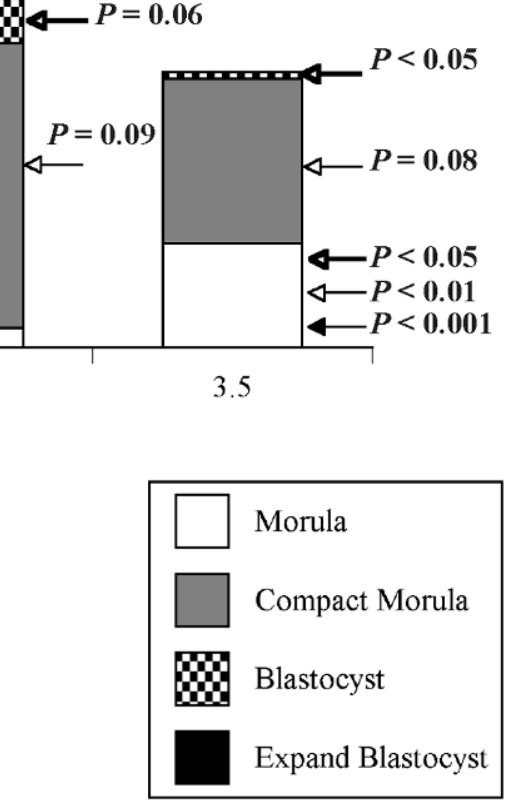

Expand Blastocyst

Figure 2. Relationship between BCS of donor heifers and embryo production shown as the developmental stages, (a) number of each class of embryo and (b) proportion of each class of embryo to the sum of excellent, good, fair, and poor embryos. In the concentric circle graph (b), the innermost zone, the next inner zone, the outer zone, and the outermost zone show the proportion of BCS-2.75, BCS-3.00, BCS-3.25, and BCS-3.5 donor heifers, respectively.

the sum of excellent, good, fair, and poor embryos than $2.75,3.00$, or 3.25 BCS heifers, as shown in the concentric circle graph (Figure $2 \mathrm{~b}$ ). In contrast, 2.75 BCS heifers tended to have more blastocysts than $3.25(P=0.06)$ and $3.50(P<0.05)$ BCS heifers (Figure $2 \mathrm{a})$.

There was no significant difference in blood glucose concentrations among $2.75(4.8 \pm 0.2 \mathrm{mM}), 3.00(4.9 \pm$ $0.1 \mathrm{mM}), 3.25(4.9 \pm 0.1 \mathrm{~m} M)$, or $3.50(5.0 \pm 0.2 \mathrm{mM})$ BCS heifers. The 3.50 BCS heifers had significantly higher $(155.8 \pm 14.0 \mathrm{p} M, P<0.05)$ blood insulin concentrations than 2.75 BCS heifers $(125.6 \pm 15.1 \mathrm{p} M)$ but not than $3.00(137.8 \pm 6.2 \mathrm{p} M)$ or $3.25(141.2 \pm 5.8 \mathrm{pM})$ BCS heifers.
We found a smaller number of excellent/good grade embryos in 3.50 BCS heifers than 3.00 or $3.25 \mathrm{BCS}$ heifers. Possible reasons for such differences include the following: (1) disadvantage follicle recruitment (Gutierrez et al., 1997; Nolan et al., 1998); (2) compromised morphological and functional quality of oocytes for fertilization and development (Lozano et al., 2003; Freret et al., 2006); (3) change in ovarian steroidogenesis (Nolan et al., 1998; Armstrong et al., 2002); and (4) excess metabolic hormones and cytokines lead to suppressing embryo development.

Hyperinsulinemia is associated with fewer medium (4 to $8 \mathrm{~mm}$ )-sized follicles, the low maturation rate in 
vitro of oocytes collected by ultrasound-guided transvaginal follicular aspiration, and the low rate of blastocyst formation in moderately fat and well-fed heifers (Adamiak et al., 2005). The dietary-induced increase in insulin concentration seems to have a direct effect on steroidogenesis in follicles and follicle dynamics (Armstrong et al., 2002). Because 3.5 BCS heifers in the present study were hyperinsulinemic, this condition may be an important factor, if not all, in their compromised embryo production. Our data suggested the adverse effect of high BCS on development. However, we must be cautious in drawing a conclusion that high BCS affect the development only at the step from the morula to the blastocyst stage, although 3.50 BCS heifers produced significantly more morula than $2.75,3.00$, and 3.25 BCS heifers, and they produced fewer blastocysts than 2.75 BCS heifers. The embryos collected from high-BCS donors may be in slower development, and at an earlier stage of development on $d 7$, because of unknown mechanisms induced by high BCS. Further studies are required to clarify such mechanisms; however, one possible reason may be inappropriate signaling by maternally derived adipocytokines, for example, tumor necrosis factor- $\alpha$ (Daniel et al., 2003; Soto et al., 2003). The present study cannot provide evidence for these mechanisms, but it highlights the need to better understand the potentially interactive effects of higher BCS and hyperinsulinemia on embryo production also in field conditions.

About 8\% of all heifers were BCS 3.50 in the present study, although we utilized stanchions in the free-stall barn to avoid social status preventing inferior heifers from having enough feed. A more strict and precise system to control the feed intake of each heifer based also on the BCS may be required to obtain maximum superovulation responses in Holstein yearling heifers for the MOET program for genetic improvement.

In conclusion, our results suggested no significant effect of BCS around 3.0 on embryo production, whereas 3.5 BCS heifers may have poorer embryo production.

\section{REFERENCES}

Adamiak, S. J., K. Mackie, R. G. Watt, R. Webb, and K. D. Sinclair. 2005. Impact of nutrition on oocyte quality: Cumulative effects of body composition and diet leading to hyperinsulinemia in cattle. Biol. Reprod. 73:918-926.

Agriculture, Forestry and Fisheries Research Council Secretariat. 1999. Japanese Feeding Standard for Dairy Cattle. Cent. Assoc. Livest. Industry, Tokyo, Japan.

Armstrong, D. G., J. G. Gong, J. O. Gardner, G. Baxter, C. O. Hogg, and R. Webb. 2002. Steroidogenesis in bovine granulosa cells: The effect of short-term changes in dietary intake. Reproduction 123:371-378.

Callesen, H., P. Lovendahl, A. Bak, and T. Greve. 1995. Factors affecting the developmental stage of embryos recovered on day 7 from superovulated dairy cattle. J. Anim. Sci. 73:1539-1543.

Daniel, J. A., T. H. Elsasser, C. D. Morrison, D. H. Keisler, B. K. Whitlock, B. Steele, D. Pugh, and J. L. Sartin. 2003. Leptin, tumor necrosis factor- $\alpha$ (TNF), and CD14 in ovine adipose tissue and changes in circulating TNF in lean and fat sheep. J. Anim. Sci. 81:2590-2599.

Edmonson, A. J., I. J. Lean, L. D. Weaver, T. Farver, and G. Webster. 1989. A body condition scoring chart for Holstein dairy cows. J. Dairy Sci. 72:68-78.

Freret, S., B. Grimard, A. A. Ponter, C. Joly, C. Ponsart, and P. Humblot. 2006. Reduction of body-weight gain enhances in vitro embryo production in overfed superovulated dairy heifers. Reproduction 131:783-794.

Gutierrez, C. G., J. Oldham, T. A. Bramley, J. G. Gong, B. K. Campbell, and R. Webb. 1997. The recruitment of ovarian follicles is enhanced by increased dietary intake in heifers. J. Anim. Sci. 75:1876-1884.

Kafi, M., and M. R. McGowan. 1997. Factors associated with variation in the superovulatory response of cattle. Anim. Reprod. Sci. 48:137-157.

Lindner, G. M., and R. W. Wright Jr. 1983. Bovine embryo morphology and evaluation. Theriogenology 20:407-416.

Lozano, J. M., P. Lonergan, M. P. Boland, and D. O'Callaghan. 2003. Influence of nutrition on the effectiveness of superovulation programmes in ewes: Effect on oocyte quality and post-fertilization development. Reproduction 125:543-553.

Nolan, R., D. O'Callaghan, R. T. Duby, P. Lonergan, and M. P. Boland. 1998. The influence of short-term nutrient changes on follicle growth and embryo production following superovulation in beef heifers. Theriogenology 50:1263-1274.

Soto, P., R. P. Natzke, and P. J. Hansen. 2003. Actions of tumor necrosis factor- $\alpha$ on oocyte maturation and embryonic development in cattle. Am. J. Reprod. Immunol. 50:380-388.

Yaakub, H., D. O'Callaghan, and M. P. Boland. 1999. Effect of type and quantity of concentrates on superovulation and embryo yield in beef heifers. Theriogenology 51:1259-1266. 